\title{
Sinopse da tribo Crotoneae Dumort. (Euphorbiaceae s.s.) no Estado de São Paulo, Brasil
}

\author{
Maria Beatriz Rossi Caruzo ${ }^{1,2,3}$ e Inês Cordeiro ${ }^{1}$
}

Recebido: 18.10.2005; aceito: 23.12.2007

\begin{abstract}
Synopsis of the tribe Crotoneae Dumort. (Euphorbiaceae s.s.) in the State of São Paulo, Brazil). Two genera, Astraea Klotzsch, with two species, and Croton L., with 37 species, were recognized for the tribe Crotoneae in the state of São Paulo. Keys for genera and species are presented, as well as illustrations of diagnostic characters. The original publication, synonymous, geographic distribution and vegetation of occurrence are refered to each species, along a voucher specimen. A new combination is proposed, Astraea cincta (Müll. Arg.) Caruzo \& Cordeiro, for Croton cinctus Müll. Arg., and one neotype and 17 lectotypes are here designated.
\end{abstract}

Key words: Astraea, Croton, nomenclature notes

RESUMO - (Sinopse da tribo Crotoneae Dumort. (Euphorbiaceae s.s.) no Estado de São Paulo, Brasil). A tribo Crotoneae está representada no Estado pelo gênero Astraea Klotzsch, com duas espécies e Croton L., com 37. São apresentadas chaves de identificação para os gêneros e espécies e ilustrações de características diagnósticas. Para cada uma das espécies são referidos a publicação original, sinônimos, distribuição geográfica e o tipo de vegetação em que ocorre, juntamente com uma coleção representativa de herbário. Uma nova combinação, Astraea cincta (Müll. Arg.) Caruzo \& Cordeiro, é proposta para Croton cinctus Müll. Arg. e são aqui designados 17 lectótipos e um neótipo.

Palavras-chave: Astraea, Croton, notas nomenclaturais

\section{Introdução}

A família Euphorbiaceae s.s. como encontra-se delimitada em Chase et al. (2002), APG II (2003) e Wurdack et al. (2005) é uma das maiores, mais diversas e complexas das Angiospermas. Selecionando-se da listagem das Euphorbiaceae s.lat. (Govaerts et al. 2000), encontram-se cerca de 245 gêneros e aproximadamente 6.300 espécies de Euphorbiaceae s.s. distribuídas em todo o globo, principalmente nas regiões tropicais. No Estado de São Paulo a família está representada por 37 gêneros e cerca de 160 espécies.

Segundo Webster (1994), a tribo Crotoneae Dumort, além do grande gênero pantropical Croton L., incluiria os pequenos gêneros Mildbraedia Pax (África), Fahrenheitia Reichb. f. \& Zoll. (Ásia) e Moacroton Croizat (Caribe).

Os estudos com as Euphorbiaceae s.s. de Berry et al. (2005a, b) e Wurdack et al. (2005), baseados em dados moleculares, indicaram diferentes afinidades para o gênero Croton, que incluem Ophellantha Standl. (América Central e Caribe), Sandwithia Lanj. (Guianas e Amazônia), Sagotia Baill.(Amazônia) e Brasiliocroton P.E. Berry \& Cordeiro, este último gênero recentemente descrito para o leste do Brasil (Berry et al. 2005a), além de Astraea Klotzch (neotropical), gênero restabelecido por Berry et al. (2005a) a partir de Croton sect. Astraea (Klotzsch) Baill.

O gênero Julocroton Mart., reconhecido em trabalhos clássicos sobre a família, como o Prodromus de De Candolle (Müller 1866) e a Flora brasiliensis (Müller 1873), foi sinonimizado por Webster (1992) e tratado como uma seção de Croton. Os estudos de Berry et al. (2005a, b) e Wurdack et al. (2005) justificaram filogeneticamente a sinonimização de Julocroton em Croton e também demonstraram a necessidade de exclusão de Croton sect. Astraea (Klotzsch) Baill., de maneira a tornar o gênero Croton monofilético.

1. Seção de Curadoria do Herbário, Instituto de Botânica, Caixa Postal 3005, 01061-970 São Paulo, SP, Brasil

2. Departamento de Botânica, Instituto de Biociências, Universidade de São Paulo, Caixa Postal 11461, 05422-970 São Paulo, SP, Brasil

3. Autor para correspondência: mbrcaruzo@hotmail.com 
Em qualquer das circunscrições da tribo Crotoneae, os únicos gêneros representados no Estado de São Paulo são Croton e Astraea. Croton é o segundo maior gênero das Euphorbiaceae s.s., com cerca de 1.200 espécies (Govaerts et al. 2000), principalmente das regiões tropicais de todo o globo, mas também de áreas subtropicais e temperadas do hemisfério norte. Na região neotropical seus principais centros de diversidade encontram-se no Brasil, Antilhas e México (Burger \& Huft 1995). No Brasil ocorrem cerca de 300 espécies, que incluem ervas, subarbustos, arbusto e árvores, concentradas principalmente no leste do Brasil, em cerrados, campos rupestres e caatingas, com um menor número de espécies em matas secas e úmidas. Astraea conta com pouco mais de dez espécies subarbustivas ou arbustivas que, com exceção de Astraea lobata (L.) Klotzsch, encontrada em toda a região neotropical, restringem-se à América do Sul, principalmente no leste e centro-oeste do Brasil, em vegetação aberta ou clareiras e bordas de florestas secas ou mais raramente úmidas.

\section{Material e métodos}

O presente trabalho foi baseado na análise de coleções depositadas nos principais herbários brasileiros, com especial destaque para os do Estado de São Paulo (BOTU, ESA, ESALQ, HRCB, IAC, MBM, PMSP, R, RB, SJRP, SP, SPF, SPSF, UB, UEC), além do estudo em campo de populações de algumas espécies.

A descrição do gênero Croton foi feita com base nas características das espécies brasileiras, este aspecto merece menção, uma vez que em espécies extra-brasileiras o ovário pode possuir menos de 3 carpelos, assim como os frutos podem ser indeiscentes.

Por ter sido muito visitado por vários botânicos no século XIX, com especial destaque para Willian John Burchell, Auguste de Saint Hilaire, Georg Heinrich Langsdorf, Albert Loefgren, Peter Wilhelm Lund, Karl Friederich Phillip Martius, Ludwig Riedel, Friederich Sellow e Johann Eugen B. Warming (Urban 1906, Hoehne et al. 1941) várias foram as espécies descritas com base em coleções do Estado de São Paulo, para as quais foi feita uma busca minuciosa em herbários europeus, principalmente $\mathrm{C}, \mathrm{G}, \mathrm{K}, \mathrm{M}$ e $\mathrm{P}$, através do exame de fotos, imagens digitais ou estudo de coleções herborizadas.
Para cada uma das espécies são referidas: publicação original, coleções tipo, basiônimo, novos sinônimos, nomes populares compilados dos rótulos de herbário, distribuição geográfica, tipo de vegetação de ocorrência e um material selecionado de herbário, além da chave de identificação para os gêneros e espécies.

\section{Resultados e Discussão}

No Estado de São Paulo o gênero Astraea Klotzsch está representado por duas espécies e Croton por 37.

Dentre as espécies de Croton, cinco encontram-se na "Lista oficial das espécies da Flora de São Paulo ameaçadas de extinção", publicada na resolução SMA 48 de 21 de setembro de 2004 da Secretaria do Meio Ambiente, sendo uma considerada "Em perigo crítico" (C. leptobotryus) e quatro "Em perigo" (C. compressus, C. glechomifolius, C. serratifolius e C. sphaerogynus). Croton sancti-crucis, apesar de não ter sido incluído na lista, enquadra-se, de acordo com os critérios estabelecidos, na categoria "Em perigo crítico", enquanto Astraea cincta e Croton fuscus, talvez estejam extintos no Estado de São Paulo. Cumpre lembrar que as informações relativas às espécies acima citadas, referem-se apenas às suas populações no Estado de São Paulo.

Chave para os gêneros da tribo Crotoneae do Estado de São Paulo

1. Ervas, subarbustos ou arbustos; folhas inteiras a profundamente 3-5 lobadas; receptáculo das flores estaminadas glabro; pétalas densamente barbadas nas margens, junto à base, com tricomas curtos; estiletes avermelhados; sementes tetragonais Astraea

1. Subarbustos, arbustos ou árvores; folhas sempre inteiras; receptáculo das flores estaminadas piloso; pétalas vilosas ao longo das margens, com tricomas longos; estiletes alvos a esverdeados; sementes globosas, subglobosas a elipsóides Croton

\section{Astraea Klotzsch}

Ervas, subarbustos ou arbustos, indumento de tricomas estrelados nos ramos e folhas; folhas simples, 
geralmente lobadas a raramente inteiras, às vezes os dois tipos na mesma planta, alternas, com estípulas; pecíolo desprovido de glândulas no ápice. Inflorescências terminais, do tipo tirso, cimeiras proximais geralmente com flores pistiladas e estaminadas, as distais unicamente com flores estaminadas; flores estaminadas diclamídeas, pétalas densamente barbadas nas margens, junto à base, com tricomas simples, curtos; receptáculo glabro, disco de 5 glândulas opostas as sépalas, estames ca. 15, encurvados no botão, filetes glabros; flores pistiladas com sépalas lanceoladas e pétalas reduzidas ou ausentes, disco inteiro, estiletes geralmente multifidos, raramente 2-fidos, avermelhados; ovário subcilíndrico, 3-carpelar, 3-locular, um óvulo anátropo por lóculo. Fruto cápsula septicida-loculicida, de deiscência explosiva; sementes tetragonais, fortemente verrucosas, carunculadas.

Chave para espécies de Astraea Klotzsch do Estado de São Paulo

1. Plantas com xilopódio. Folhas inteiras, subcartáceas, de margens cartilaginosas, inconspicuamente serrilhadas ........ A. cincta

1. Plantas desprovidas de xilopódio. Folhas 3-5 lobadas, membranáceas, de margens conspicuamente serrilhadas a crenadas

.. lobata

Astraea cincta (Müll. Arg.) Caruzo \& Cordeiro comb. nov. Croton cinctus Müll. Arg., Fl. Bras.11(2): 235. 1873. TIPO: BRASIL. São PAULO: Rio Pardo, Riedel 608 (holótipo G!)

Material adicional examinado: BRASIL. GoIÁs: Município de Chapadão do Céu e Mineiros, Parque Nacional das Emas, 10-III-1999, M.A. Batalha 3109 (SP). Mato Grosso do Sul: Campo Grande, 6-VIII-1936, F.C. Hoehne \& A. Gehrt s.n. (SP 35784).

Espécie dos cerrados do Brasil Central (GO, MS e SP). No Estado de São Paulo a única referência para a espécie é seu holótipo.

Astraea lobata (L.) Klotzsch, Arch. Naturgesch. 7(1): 194. 1841. Croton lobatus L., Sp. Pl. 2: 1005. 1753. TIPO: [MÉXICO], VERACRUZ, Houston s.n. (lectótipo n.v. BM - Cliffort Herbarium indicado por Webster, Contr. Univ. Mich. Herb. 23: 375. 2001).

Astraea paulina Didr., Vidensk. Meddel. Dansk Naturhist. Foren. Kjobenhavn part. 8-10: 138. 1857. Croton lobatus var. paulinus (Didr.) Müll. Arg. in DC., Prodr. 15(2): 667. 1866. Croton paulinus (Didr.) Müll. Arg., Fl. Bras. 11(2): 236. 1873. TIPO: BRASIL. São Paulo: Itu, II-1834, Lund s.n. (holótipo C!) syn. nov.

Figuras $1 \mathrm{~K}_{1}-\mathrm{K}_{3}$

Material selecionado: BRASIL. São PAULO: Campinas, 31-III-2004, M.B.R. Caruzo et al. 55 (SP, WIS).

Espécie herbácea a subarbustiva, invasora, de ampla distribuição geográfica: Sul dos Estados Unidos e toda a América tropical. (Govaerts et al. 2000), Brasil (MA, PA, RN, PB, PE, BA, GO, MT, MS, MG, ES, RJ, SP, PR, SC, RS). Cerrado, beira de florestas ombrófilas e mesófilas perturbadas e terrenos cultivados. Como não houve indicação clara do lectótipo em Webster (2001), através da expressão hic designatus ou here designated, da maneira em que determina o Código Internacional de Nomenclatura Botânica (McNeill et al. 2006), o tipo de Astraea lobata ainda não se encontra designado.

\section{Croton L.}

Subarbustos, arbustos ou árvores, indumento de tricomas estrelados, estrelado-lepidotos ou lepidotos; folhas simples, sempre inteiras, alternas, com estípulas; ápice do pecíolo ou base do limbo, freqüentemente com glândulas, estipitadas ou sésseis. Inflorescências terminais, do tipo tirso, cimeiras geralmente com flores pistiladas na porção proximal da raque e estaminadas na terminal, mais raramente com flores pistiladas e estaminadas na porção proximal; flores estaminadas diclamídeas, pétalas geralmente vilosas nas margens, principalmente junto à base, com tricomas simples, longos, receptáculo piloso; disco de 5 glândulas opostas as sépalas, raramente inteiro, estames 10-100, encurvados no botão; flores pistiladas com pétalas reduzidas ou ausentes, disco inteiro, raramente dividido, estiletes bífidos a multifidos, alvos a esverdeados, ovário 3-carpelar, 3-locular, um óvulo anátropo por lóculo. Fruto cápsula septicida-loculicida, de deiscência explosiva; sementes globosas, subglobosas a elipsóides, carunculadas, lisas a verrucosas. 
Chave para espécies de Croton L. do Estado de São Paulo

1. Folhas com glândulas no ápice do pecíolo ou base da lâmina

2. Estiletes 2-fidos

3. Subarbustos prostrados. Folhas suborbiculares a reniformes, ca. $1 \mathrm{~cm}$ compr...... C. glechomifolius

3. Árvores a arbustos eretos. Folhas ovais, oval-lanceoladas a cordiformes, igual ou maiores que $2 \mathrm{~cm}$ de compr.

4. Inflorescências com címulas proximais de flores estaminadas e pistiladas, distais estaminadas

5. Folhas oval-lanceoladas. Glândulas do pecíolo estipitadas. Estames ca. 30 ... C. macrobothrys

5. Folhas ovais a cordiformes. Glândulas do pecíolo sésseis. Estames 15-21

6. Indumento de tricomas estrelados. Folhas com margem inteira a inconspicuamente serrilhada. Flores pistiladas subsésseis; pétalas reduzidas a glândulas globosopateliformes

C. gracilipes

6. Indumento de tricomas dendríticos, adpresso-estrelados ou estrelados. Folhas com margem inteira a irregularmente serrilhada. Flores pistiladas pediceladas; pétalas filiformes

7. Árvore das florestas mesófilas, até $24 \mathrm{~m}$ alt. Látex incolor. Folhas ovais. Estípulas linear-lanceoladas, ca. $1 \mathrm{~mm}$ compr. Fruto oboval, 3-gono. Sementes subglobosas, com testa lisa

C. piptocalyx

7. Árvoreta das matas ciliares e capoeiras de florestas mesófilas, até $10 \mathrm{~m}$ alt. Látex avermelhado. Folhas cordiformes. Estípulas foliáceas, subuladas, ca. $5 \mathrm{~mm}$ compr. Fruto globoso. Sementes globosas, com testa levemente verruculosa..... C. urucurana

4. Inflorescências com todas as címulas de um único tipo

8. Folhas com margem inconspicuamente a miudamente serrilhada. Pétalas reduzidas a glândulas globosas

9. Planta glabrescente. Estípulas triangulares; glândulas do pecíolo estipitadas. Flores estaminadas pediceladas

C. leptobotryus

9. Planta pubescente. Estípulas lanceoladas; glândulas do pecíolo sésseis. Flores estaminadas subsésseis C. sancti-crucis

8. Folhas com margem serreada a grosseiramente denteada. Pétalas filiformes

10. Folhas com margem grosseiramente denteada. Eixo da inflorescência sem flores entre as címulas estaminadas e pistiladas. Brácteas desprovidas de glândulas

C. lundianus

10. Folhas com margem serrilhada a irregularmente serreada. Eixo da inflorescência com as címulas pistiladas contíguas às estaminadas. Brácteas com glândulas lageniformes

11. Ramos jovens pubescentes, tricomas estrelados. Glândulas do pecíolo sésseis

a subsésseis. Brácteas com glândulas sésseis. Ovário piloso C. glandulosus

11. Ramos jovens hirsutos, tricomas estrelados e estrelado-porrectos. Glândulas do pecíolo estipitadas. Brácteas com glândulas longamente estipitadas. Ovário hirsuto C. hirtus

2. Estiletes 4-fidos ou mais

12. Inflorescências com todas as címulas com flores de um único tipo

13. Ramos jovens pubescentes. Folhas com margem inteira, sem glândulas; nervação eucamptódroma. Glândulas do pecíolo adpressas, às vezes recobertas pelo indumento.

Pétalas da flor pistilada subuladas, com glândula no ápice.....

C. lanatus

13. Ramos jovens hirsutos. Folhas com margem irregularmente a grosseiramente denteada, com glândulas; nervação cladódroma; glândulas do pecíolo não-adpressas. Pétalas da flor pistilada ausentes ou inconspícuas 
14. Címulas pistiladas separadas das estaminadas por um trecho vazio na raque. Disco das flores estaminadas inteiro, 5-lobado. Flores pistiladas sésseis; sépalas 6 C. sclerocalyx

14. Címulas pistiladas contíguas às estaminadas. Disco estaminado 5-segmentado. Flores pistiladas pediceladas; sépalas 5 C. antisyphiliticus

12. Inflorescências com címulas proximais de flores pistiladas e estaminadas, distais estaminadas

15. Glândulas do pecíolo sésseis

16. Espécie da floresta mesófila. Folhas ovais, base cuneada a levemente truncada. Flores estaminadas campanuladas. Flores pistiladas pediceladas. Indumento do ápice do fruto enegrescido C. rottlerifolius

16. Espécie da floresta de restinga. Folhas ovais a oval-lanceoladas, base cordada, com lobos sobrepostos. Flores estaminadas rotáceas. Flores pistiladas subsésseis. Indumento do fruto incolor C. sphaerogynus

15. Glândulas do pecíolo estipitadas

17. Árvores com tricomas lepidotos

18. Indumento rufo-argênteo; ramos angulosos; lobos do cálice não acrescentes no fruto C. salutaris

18. Indumento argênteo; ramos cilíndricos; lobos do cálice conspicuamente acrescentes no fruto C. hemiargyreus

17. Árvores a arbustos com tricomas estrelados, adpresso-estrelados ou dendríticos 19. Estames 80-130 C. vulnerarius

19. Estames 18-60

20. Folhas largamente elípticas a obovais; margem crenada. Estames ca. 18. Flores pistiladas longamente pediceladas; sépalas arredondadas, reduplicativas

C. priscus

20. Folhas ovais a cordiformes; margem inconspícuamente serrilhada a irregularmente serreada. Estames 50-60. Flores pistiladas subsésseis a pediceladas; sépalas ovais a oval-lanceoladas, valvares

21. Flores pistiladas levemente campanuladas, sésseis a subsésseis; lobos do cálice ovais, foliáceos, ca. $8 \mathrm{~mm}$ compr.; estiletes unidos na base C. alchorneicarpus

21. Flores pistiladas rotáceas, geralmente pediceladas, raramente subsésseis; lobos do cálice oval-lanceolados, inconspícuos, ca. $3 \mathrm{~mm}$ compr.; estiletes livres C. celtidifolius

1. Folhas desprovidas de glândulas no ápice do pecíolo ou base do limbo (C. organensis cujas glândulas são maculares e extremamente inconspicuas no material herborizado, está aqui incluído) 22. Flores estaminadas com 3 lobos do cálice cuculados; as pistiladas com os 3 lobos maiores do cálice profundamente laciniados, os 2 menores inconspícuos

23. Subarbustos com xilopódio, folhas oblongas, rômbicas, lanceoladas, orbiculares ou ovais; tricomas estrelados, com raios maiores que a metade do estípite; disco da flor pistilada profundamente 3-lobado; sementes lisas; plantas de cerrado e formações campestres C. didrichsenii

23. Subarbustos a arbustos desprovidos de xilopódio, folhas cordadas a largamente elípticas, lanceoladas a oval-lanceoladas; tricomas estrelados, com raios menores que a metade de seus estípites; disco da flor pistilada inteiro a levemente 3-lobado; sementes reticuladas; plantas invasoras ou típicas de vegetação alterada, geralmente de beira de matas ou capoeiras 
24. Inflorescências com tricomas alvos a ferrugíneos; brácteas espatuladas a suborbiculares, com margens inteiras a serrilhadas ou profundamente denteadas; estiletes 4-fidos C. triqueter

24. Inflorescências com tricomas alvos entremeados de negros, com aparência fuliginosa; brácteas espatuladas, com margens inteiras a esparsamente denteadas; estiletes 2-fidos C. fuscescens

22. Flores estaminadas com todos os lobos do cálice iguais, planos; as pistiladas com todos os lobos inteiros

25. Estiletes 2-fidos

26. Plantas de cerrado, indumento de tricomas exclusivamente estrelados. Folhas com margem inteira a miudamente serrilhada. Flores estaminadas e pistiladas com sépalas recobertas por tricomas estrelados

27. Estames ca. 18. Flores pistiladas curtamente pediceladas; disco inconspícuamente 5-lobado. Fruto globoso, piloso a hirsuto. Sementes com testa lisa C. grandivelus

27. Estames ca. 11. Flores pistiladas conspicuamente pediceladas; disco profundamente 5-lobado. Fruto subgloboso a elipsóide, glabrescente, freqüientemente encurvado no pedicelo. Sementes com testa levemente verruculosa C. pedicellatus

26. Plantas de campo, indumento de tricomas estrelados, adpresso-estrelados, estreladolepidotos ou exclusivamente lepidotos. Folhas com margem inteira. Flores estaminadas e pistiladas com sépalas recobertas por tricomas adpresso-estrelados, estreladolepidotos ou lepidotos

28. Folhas com indumento de tricomas estrelados na face adaxial e adpressoestrelados ou estrelado-lepidotos na face abaxial

29. Folhas lanceoladas; lâmina 0,3-3×0,1-0,6 cm. Flores pistiladas campanuladas; lobos do cálice lanceolados a espatulados; estiletes 2-fidos, ramos inteiros a 2-fidos C. serpyllifolius

29. Folhas elípticas a oval-lanceoladas; lâmina 1-6×0,5 -1,7 cm. Flores pistiladas subcampanuladas; lobos do cálice ovais a arredondados; estiletes 2-fidos, ramos inteiros C. ceanothifolius

28. Folhas com indumento de tricomas exclusivamente lepidotos

30. Folhas com face adaxial glabra, raro escabra, abaxial lepidota. Flores pistiladas campanuladas, lobos do cálice oval-lanceolados a oblongos C. dichrous

30. Folhas com ambas as faces lepidotas. Flores pistiladas subcampanuladas, lobos do cálice elípticos, ovais a obovais C. erythroxyloides

25. Estiletes 4 ou mais fidos

31. Cálice da flor pistilada recoberto por tricomas glandulares

32. Folhas tomentosas na face abaxial, eucamptódromas. Brácteas ca. $5 \mathrm{~mm}$, ovais, com ápice longamente acuminado, pubescentes, esparsamente glandulosas na base C. serratifolius

32. Folhas pubérulas na face abaxial, acródromas. Brácteas ca. 2 mm., lineares, com ápice não acuminado, glabrescentes, conspicuamente glandulosas nas margens

C. fuscus

31. Cálice da flor pistilada desprovido de tricomas glandulares

33. Inflorescências globosas, comosas. Sépalas das flores pistiladas lanceoladas; margens lacerado-glandulosas C. heterodoxus

33. Inflorescências alongadas, não-comosas. Sépalas das flores pistiladas oblongas, romboidais a oval-lanceoladas; margens inteiras

34. Ramos conspicuamente achatados. Flores estaminadas campanuladas a subcampanuladas. Flores pistiladas sésseis a subsésseis; pétalas ausentes 
35. Estípulas subuladas, com glândulas nas margens. Inflorescências com címulas com um único tipo de flor; flores estaminadas subcampanuladas; flores pistiladas campanuladas, sésseis, lobos do cálice ovais a oval-lanceolados C. compressus

35. Estípulas lineares, sem glândulas. Inflorescências com címulas basais com flores estaminadas e pistiladas; flores estaminadas rotáceas; flores pistiladas campanuladas, subsésseis, lobos do cálice romboidais C. organensis

34. Ramos cilíndricos. Flores estaminadas rotáceas a subcampanuladas. Flores pistiladas pediceladas; pétalas filiformes

36. Árvore muito comum em clareiras e borda de florestas mesófilas e ombrófilas de todo o Estado de São Paulo, com indumento de tricomas estrelados, adpresso-estrelados e dendríticos. Flores pistiladas rotáceas. Fruto globoso, verruculoso. Sementes globosas; testa lisa C. floribundus

36. Arbusto exclusivo da floresta mesófila do noroeste do Estado de São Paulo, no Município de Teodoro Sampaio, com indumento de tricomas lepidotos. Flores pistiladas campanuladas. Fruto subgloboso, liso. Sementes oblongas; testa levemente costada C. tricolor

Croton alchorneicarpus Croizat, Darwiniana 6: 451. 1944. TIPO: BRASIL. SÃo Paulo: Campos do Jordão, II-1935, Kuhlmann s.n. (holótipo SP 32455 !, isótipo A!)

Material selecionado: BRASIL. São PaUlo: Campos do Jordão, 27-II-2002, I. Cordeiro et al. 2778 (SP).

Arbusto a árvore endêmica da Serra da Mantiqueira, da floresta ombrófila montana e matas ciliares do Sudeste do Brasil (MG, SP e RJ).

Croton antisyphiliticus Mart., Reise Bras. 1: 282. 1823. TIPO: BRASIL. São PAULO: Martius s.n. (holótipo M!).

Croton caperoniifolius Müll. Arg. Fl. Bras. 11(2): 206. 1873. TIPO: BRASIL. Minas GeraIS: Lagoa Santa, 1863, Warming 1572 (lectótipo C! aqui designado). São Paulo: "ad Rio Pardo prov. S. Paulo", Riedel s.n. (síntipo n.v.) syn. nov.

Figura $1 \mathrm{~A}_{1}-\mathrm{A}_{2}$

Material selecionado: BRASIL. São Paulo: Pedregulho, 12-XI-1994, W. Marcondes-Ferreira 992 (SP, UEC).

Espécie subarbustiva, provida de xilopódio, muito comum nos cerrados e campos do Paraguai e Brasil (AM, TO, PI, BA, DF, GO, MT, MG, SP, PR, SC). Nome popular: pé-de-perdiz.

Croton ceanothifolius Baill. Adansonia 4: 295. 1864. TIPO: BRASIL. MinAs GERAIS: Saint-Hilaire D-
558 (síntipo P!), Saint-Hilaire B1-227 (síntipo P!). Croton pallidulus Baill., Adansonia 4: 296. 1864. TIPO: BRASIL. SÃo PaUlo: Saint-Hilaire cat c2 1473 (síntipo P!). syn. nov.

Croton fallax Müll. Arg., Linnaea 34: 137. 1865. TIPO: BRASIL. São PAUlo: 1839, Lund s.n. (síntipo G!); Mogi das Cruzes, XI-1833, Riedel 578 (síntipo $\mathrm{G}$ !).

Figuras $2 \mathrm{~B}_{1}-\mathrm{B}_{3}$

Material selecionado: BRASIL. São PAUlo: Campos do Jordão, 25-X-2004, M.B.R. Caruzo et al. 70 (SP, SPF, WIS).

Subarbusto dos campos de altitude do Sudeste e Sul do Brasil (MG, SP, PR, SC, RS).

Croton celtidifolius Baill., Adansonia 4: 331. 1864. TIPO: BRASIL. RIO DE JANEIRO: Saint-Hilaire s.n. [lectótipo P!, designado por Smith et al., Euforbiáceas In Flora Ilustrada Catarinense (R. Reitz ed.) p. 72-73. 1988]; 1842, Claussen s.n. (síntipo P n.v., W!); Serra dos Órgãos, 1833, Vauthier 93 (síntipos G!, P!, W!); Serra dos Órgãos, 1838, Gardner 618 (síntipo P! NY! K!).

Figura $1 \mathrm{~B}_{1}-\mathrm{B}_{2}$

Material selecionado: BRASIL. São PaUlo: Cunha, 29-XI-2004, M.B.R. Caruzo et al. 80 (SP, SPF, WIS).

Arbustos a arvoretas da floresta ombrófila montana do Sudeste e Sul do Brasil (MG, RJ, SP, PR, SC e RS). Nome popular: marmeleiro. 
Croton compressus Lam., Encycl. 2: 208. 1786. TIPO: BRASIL. RIO DE JANEIRO: 1767, Commerson s.n. (holótipo $\mathrm{P} !)$.

Figuras $1 \mathrm{C}_{1}-\mathrm{C}_{2}$

Material examinado: BRASIL. São PAulo: São Sebastião, Ilha dos Alcatrazes, 11-XII-1990, L. Rossi \& M. Aidar 1090 (SP).

Arbusto das florestas de restinga do Sudeste do Brasil (RJ, SP). Foi encontrada apenas uma única coleção da espécie para o Estado de São Paulo.

Croton dichrous Müll. Arg., Linnaea 34: 105. 1865 TIPO: BRASIL. "In Brasilia meridionalis", Sellow s.n. (holótipo B destruído, isótipos, G n.v., SP!)

Figura $1 \mathrm{D}_{1}-\mathrm{D}_{2}$

Material selecionado: BRASIL. São Paulo: Campos do Jordão, 25-X-2004, M.B.R. Caruzo \& S.E. Martins 69 (SP, SPF, WIS).

Subarbusto dos campos de altitude do Sudeste do Brasil (MG, RJ, SP).

Croton didrichsenii Webster, Novon 2(3): 271. 1992. nom. nov. para Julocroton humilis Didr. Vidensk. Meddel. Dansk Naturhist. Foren. Kjobenhavn part. 8-10: 132. 1857.TIPO: BRASIL. São PaUlo: Mogi das Cruzes, XI-1833, Lund s.n. (holótipo C!, isótipos $\mathrm{G}$ !, $\mathrm{K}$ !).

Croton cordeiroae Webster, Novon 2(3): 271. 1992. nom. nov. para Julocroton riedelianus Müll. Arg. Fl. Bras. 11(2): 278. 1873. TIPO: BRASIL. SÃO PAulo: São Carlos, Riedel s.n. (holótipo G!) syn. nov.

Croton lanceolaris Webster, Novon 2(3): 272. 1992. nom. nov. para Julocroton lanceolatus Klotzsch ex Müll. Arg. DC. Prodr. 15(2): 702. 1866. TIPO: BRASIL. São Paulo: Alegres, Riedel 2806 (holótipo B destruído, lectótipo P!, aqui designado) syn. nov.

Croton solanaceus (Müll. Arg.) Webster, Novon 2(3): 272. 1992. nom. nov. para Julocroton humilis var. solanaceus Müll. Arg. DC. Prodr. 15(2): 701. 1866. Julocroton solanaceus (Müll. Arg.) Müll. Arg. Fl. Bras.11(2): 279. 1873.TIPO: BRASIL. Sellow s.n. (holótipo B destruído, lectótipo G!, aqui designado, isótipos $\mathrm{K}$ !, P!) syn. nov.

Material selecionado: BRASIL. S̃̃o PAULO: Buritizal, 20¹2'26,4”'S e 4745'22,7''W, 27-VII-1994, K.D. Barreto et al. 2739a (ESA, SP).
Subarbusto dos campos limpos e cerrados da Bolívia, Paraguai, Argentina, Uruguai e Brasil (BA, DF, GO, MG, MS, MT, PR, SC, SP, RS).

Croton erythroxyloides Baill., Adansonia 4: 297. 1864. TIPO: BRASIL. Minas GERAIS: Saint-Hilaire cat. B2- 2245 pp. (holótipo P!).

Figura $1 \mathrm{E}_{1}-\mathrm{E}_{2}$

Material selecionado: BRASIL. São PAULO: São Bento do Sapucaí, 2241'24'S, 45³9'27' W, 27-X-2004, M.B.R. Caruzo et al. 74 (SPF, SP, WIS).

Arbusto dos campos de altitude do sudeste do Brasil (MG, RJ e SP)

Croton floribundus Spreng., Syst. veg. 3: 873. 1826. TIPO: BRASIL. Sellow s.n. (holótipo B destruído. BRASIL. Sellow 171 (neótipo SP!, aqui designado).

Figuras $1 \mathrm{~F}_{1}-\mathrm{F}_{3}$

Material selecionado: BRASIL. São PAUlo: Taguaí, 28-IX-1995, J.Y. Tamashiro et al. 674 (ESA, HRBC, MEXU, SP, SPF, UEC).

Árvore pioneira, muito comum em bordas e clareiras de floresta mesófilas, ombrófilas e de matas ciliares do Paraguai e Brasil (PB, PE, BA, MS, MG, ES, RJ, SP e PR). Nomes populares: capixingui, sangue-de-dragão, cambraia.

O holótipo de Croton floribundus era uma coleção de Sellow pertencente ao herbário de Berlim. Em virtude da destruição praticamente total de todas as Euphorbiaceae deste herbário, durante a Segunda Grande Guerra, há necessidade de se indicar um novo espécime tipo. A lectotipificação de um isótipo, que seria o ideal, é inviável, uma vez que o holótipo não possuía número ou indicação de localidade, apenas "Brasília meridionalis", como muitas das coleções de Sellow que encontravam-se em Berlim (Urban 1906). Como foram localizadas outras coleções de $C$. floribundus realizadas por Sellow no Brasil, escolhemos entre elas a de número 171 do Herbário SP para designar como neótipo da espécie, em virtude de seu bom estado de conservação e por possuir flores pistiladas e estaminadas.

Croton fuscescens Spreng., Syst. veg. 3: 874. 1826. TIPO: BRASIL. Rio de Janeiro: Sellow s.n. (holótipo B destruído, lectótipo BR!, aqui designado). 
Croton microcalyx (Müll. Arg.) Webster, Novon 2(3): 272. 1992. Julocroton microcalyx Müll. Arg. Linnaea 34: 142. 1865. TIPO: BRASIL. SÃo Paulo: Salto de Itu, Riedel 2180 (holótipo B destruído, lectótipo BM!, aqui designado, isolectótipos F!, GH!, K!, NY!, P!) syn. nov.

Material selecionado: BRASIL. SÃo PAULO: São Paulo, 1-XI-2001, M.B.R. Caruzo \& I. Cordeiro 01 (SP).

Espécie arbustiva das bordas e clareiras de florestas ombrófilas e mesófilas da Argentina e Brasil (BA, ES, MG, PR, PE, RJ, SP).

Croton fuscus (Didr.) Müll. Arg., Linnaea 34: 131. 1865. Miriogomphos fuscus Didr., Vidensk. Meddel. Dansk Naturhist. Foren. Kjobenhavn part. 8-10: 143. 1857. TIPO: BRASIL. SÃo PAULO: Franca,VI-1834, Lund s.n. ( holótipo C!, isótipo GH!)

Croton leucadenius Baill., Adansonia 4: 338. 1864. TIPO: BRASIL. São PaUlo: "campos près la fazenda du Fortaleza", Saint-Hilaire cat. C2 1467 (lectótipo P!, aqui designado); BRASIL. 1833, Gaudichaud-Beaupré 952 (P, síntipo n.v.), Sellow s.n. (B, síntipo destruído) syn. nov.

Material adicional examinado: BRASIL. MATO GROSSO DO Sul: entre Dourados e Ponta Porã, 5-II-1952, E. Kuhlmann s.n. (SP 69956)

Espécie arbustiva do cerrado, registrada para São Paulo e Mato Grosso do Sul. Além do holótipo, do lectótipo do sinônimo e um dos síntipos citados por Baillon (1864) e mais duas coleções de Riedel citadas por Muller $(1865,1866,1873)$, não há registro de outras coletas da espécie no Estado. Govaerts et al. (2000) sinonimizaram erroneamente $C$. fuscus a C. leucadenius, evidentemente por terem ignorado o basiônimo da primeira, publicado anteriormente a C. leucadenius.

Croton glandulosus L., Syst. nat. ed. 10: 1275. 1759. TIPO: [JAMAICA], Browne (Lectótipo Herb. LINN no 1140.7!, designado por Fawcett \& Rendle in Fl. Jamaica 4: 285. 1920.

Figuras $1 \mathrm{G}_{1}-\mathrm{G}_{2}$

Material selecionado: BRASIL. São PAulo: Pedregulho, 20¹4'52'”S, 47²7'37'”W, 15-II-2004, M.B.R. Caruzo et al. 37 (SP).

Subarbusto invasor de ampla distribuição geográfica: Estados Unidos da América, México, América Tropical (Govaerts et al. 2000), Brasil (AP,
AM, PA, MA, PE, BA, GO, DF, MT, MS, ES, MG, RJ, SP, PR, SC, RS). Encontrado em cerrado, beiras e clareiras de florestas ombrófilas e mesófilas. Nomes populares: carvão-branco, gervão-branco.

Croton glechomifolius Müll. Arg., Linnaea 34:126. 1865 (março). TIPO: BRASIL. "In Brasilia Meridionalis", 15-XI-1828, Sellow s.n. (holótipo B destruído, foto $\mathrm{F}$ !).

Croton tragifolius Baill., Adansonia 6: 16. 1865 (setembro). TIPO: BRASIL. SÃo PAULO: "bord du chemin, près le rio Verde, Saint-Hilaire cat. C2 1387 (P n.v.).

Figuras $1 \mathrm{H}_{1}-\mathrm{H}_{2}$

Material selecionado: BRASIL. São PAUlo: Bom Sucesso do Itararé, XII-1997, F. Chung et al. 7 (ESA).

Subarbusto dos campos da Argentina e Brasil (SP, PR, SC, RS).

Croton gracilipes Baill., Adansonia 4: 333. 1864. TIPO: BRASIL. Minas Gerais: 1838, Claussen 773 (lectótipo P!, aqui designado), MATo Grosso, Gaudichaud-Beaupré 250 (síntipo P!).

Material selecionado: BRASIL. São PAULO: Paulo de Faria, 195 $55^{\prime}-19^{\circ} 58^{\prime} \mathrm{S}, 4^{\circ} 32^{\prime} \mathrm{W}, 20-\mathrm{XI}-2001$, F. Tomasetto \& A.A. Rezende 187 (SP).

Arbusto a arvoreta das florestas mesófilas da Bolívia, Argentina, Paraguai e Brasil (GO, MT, MS, MG, SP, PR).

Croton grandivelus Baill., Adansonia 4: 322. 1864. TIPO: BRASIL. SÃo Paulo: Saint-Hilaire cat. C2 1358 (holótipo P!, isótipo A!).

Croton occidentalis Müll. Arg. Fl. Bras. 11(2): 159. 1873. TIPO: BRASIL. São PaUlo: Rio Pardo, Riedel 510 (holótipo B destruído, lectótipo G!, aqui designado) syn. nov.

Croton pomaderris Baill. Adansonia 4: 307. 1864. TIPO: BRASIL. São Paulo: Saint Hilaire cat. C2 1426 (holótipo P!) syn. nov.

Croton subagrarius Müll. Arg. Fl. Bras. 11(2): 174. 1873. TIPO: BRASIL. Tamberlik s.n. (síntipo W n.v.), SÃo PaUlo: Itu, 1839, Lund (lectótipo G!, aqui designado). syn. nov.

Croton pohlianus Müll. Arg., Linnaea 34: 92. 1865. TIPO: BRASIL. Sellow s.n. (síntipo B destruído), Blanchet 3323 (síntipo P n.v.), Pohl 1610 (lectótipo G!, aqui designado) syn. nov. 
Croton regnellianus Müll. Arg. Linnaea 34: 122. 1865. TIPO: BRASIL. Minas Gerais: Caldas, Regnell 399 (holótipo S n.v., isótipo P!) syn. nov.

Material selecionado: BRASIL. São Paulo: Pedregulho, 20¹4'52'S, 47²7'37'W, 17-II-2004, M.B.R. Caruzo et al. 34 (SP, WIS).

Subarbusto dos cerrados e campos da Bolívia e Brasil (DF, MT, MS, MG, RJ, SP, PR).

Croton hemiargyreus Müll. Arg., Linnaea 34: 81. 1865. TIPO: BRASIL. Minas Gerais: Caldas, Regnell I 402 (lectótipo S!, aqui designado, isolectótipos, G!, K!, NY!, P!, R!, US!, WU!), Widgren 339 (síntipo GH!).

Material examinado: Águas da Prata, I-2007, M.B.R. Caruzo et al. 112 (SP).

Arvoreta de florestas secas do sudeste do Brasil (MG, SP). No Estado de São Paulo só foi encontrada em uma única localidade.

Croton heterodoxus Baill., Adansonia 4: 309. 1864. TIPO: BRASIL. SÃo PAULO: “campos près de Jaquarihahiba", Gaudichaud-Beaupré 8 [lectótipo P!, designado por Smith et al., Euforbiáceas In Flora Ilustrada Catarinense (R. Reitz ed.) p. 94-95. 1988], Saint-Hilaire cat C2 1443 (síntipo P n.v.).

Figuras $1 \mathrm{I}_{1}-\mathrm{I}_{4}$

Material selecionado: BRASIL. SÃo PAULO: Bom Sucesso do Itararé, $24^{\circ} 16^{\prime} 14^{\prime \prime} \mathrm{S}, 49^{\circ} 15^{\prime} 35^{\prime}$ 'W, XII-1997, S.I. Elias et al. 258 (ESA).

Subarbusto dos campos do sul-sudeste do Brasil (SP, PR, SC).

Croton hirtus L' Hér., Stirp. nov. p. 17. pl. 9. 1785. TIPO: GUIANA. 1783, Richard s.n. (holótipo P n.v.).

Croton aberrans Müll. Arg. Fl. Bras. 11(2): 232. 1873. TIPO: BRASIL. São Paulo: Rio Pardo, Riedel 546 (holótipo G!). syn. nov.

Figura 1J

Material selecionado: BRASIL. SÃo PAULO: São Roque, 26-IV-1994, R.B. Torres et al. 116 (IAC, SP).

Espécie invasora subarbustiva, de ampla distribuição geográfica: Caribe, México até o norte da Argentina (Govaerts et al. 2000) e Brasil (PA, MA, PE, BA, MG, SP, PR, SC, RS), sendo encontrada em cerrados, beira de matas ombrófilas e mesófilas, pastos e plantações.
Croton lanatus Lam. Encycl. 2: 211. 1786. TIPO: URUGUAI. Montevidéu: Commerson s.n., (holótipo P!).

Croton thermarum Müll. Arg., Fl. Bras. 11(2): 151. 1873. TIPO: BRASIL. Minas Gerais: "prope Caldas, in campis juxta thermas", Regnell 1084 (holótipo C!, isótipos $\mathrm{P}$ !, $\mathrm{S}$ !). syn. nov.

Figuras $2 \mathrm{H}_{1}-\mathrm{H}_{4}$

Material selecionado: BRASIL. São PAULO: São Paulo, 26-VII-1995, R.J.F. Garcia et al. 687 (HRCB, SP, SPF, UEC).

Subarbusto a arbusto dos campos limpos e de altitude da Argentina, Uruguai e Brasil (MG, SP, PR, $\mathrm{SC}$ e RS).

Croton leptobotryus Müll. Arg., Fl. Bras. 11(2):155. 1873. TIPO: BRASIL. MinAs GERAIS: Lagoa Santa, Warming 1628 (holótipo C!).

Material selecionado: BRASIL. SÃo PAUlo: Luis

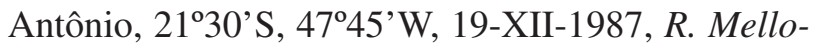
Silva et al. 42 (SP, SPF).

Subarbusto da beira de florestas mesófilas do Brasil central e Sudeste (GO, MG, SP).

Croton lundianus (Didr.) Müll. Arg., DC. Prod. 15(2): 662. 1866. Podostachys lundiana Didr., Vidensk. Meddel. Dansk Naturhist. Foren. Kjobenhavn part. 8-10: 137. 1857. TIPO: BRASIL. São PaUlo: Taubaté, XI-1833, Lund s.n. (holótipo C!).

Figuras $1 \mathrm{~L}_{1}-\mathrm{L}_{4}$

Material selecionado: BRASIL. São Paulo: Caraguatatuba, 31-I-2004, M.B.R. Caruzo et al. 22 (SP, WIS).

Espécie invasora do cerrado, beira de florestas ombrófilas e mesófilas de quase todo o Brasil (MA, BA, GO, MG, ES, RJ, SP, PR, SC, RS).

Croton macrobothrys Baill., Adansonia 4: 332. 1864. TIPO: BRASIL. Rio DE JANEIRO: "Serra dos Orgãos”, 1833, Vauthier 92 (holótipo P!), (isótipo G!, W!).

Figuras $2 \mathrm{~A}_{1}-\mathrm{A}_{4}$

Material selecionado: BRASIL. São PAULO: Caraguatatuba, IX-2000, L. Rossi et al. 2181 (SP, SPSF).

Árvore da floresta ombrófila do leste do Brasil (BA, RJ, SP, PR, SC). Nomes populares: pau-sangue, sangue-de-dragão, sangue-de-drago-de-folha-miúda, sangue-de-drago. 


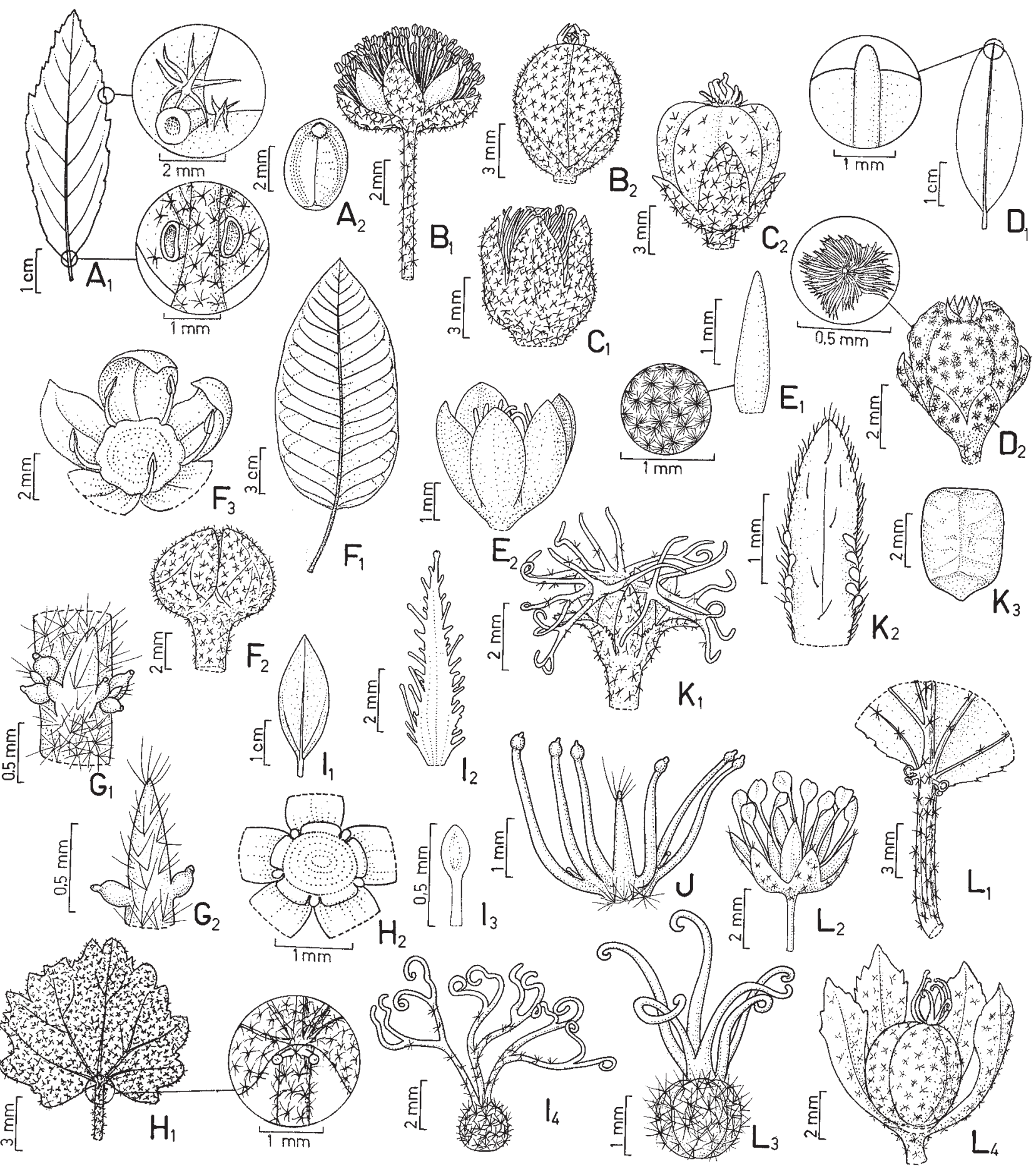

Figura 1. $\mathrm{A}_{1}-\mathrm{A}_{2}$. Croton antisyphiliticus. $\mathrm{A}_{1}$. Folha (Handro 316). $\mathrm{A}_{2}$. Semente (Souza 7106). $\mathrm{B}_{1}-\mathrm{B}_{2}$. Croton celtidifolius. $\mathrm{B}_{1}$. Flor estaminada. $\mathrm{B}_{2}$. Fruto (Caruzo 32). $\mathrm{C}_{1}-\mathrm{C}_{2}$. Croton compressus. $\mathrm{C}_{1}$. Flor pistilada (Rossi 1090). $\mathrm{C}_{2}$. Fruto (Reis 225). $\mathrm{D}_{1}-\mathrm{D}_{2}$. Croton dichrous. $\mathrm{D}_{1}$. Folha. $\mathrm{D}_{2}$. Fruto (Freitas 619). $\mathrm{E}_{1}-\mathrm{E}_{2}$. Croton erythroxyloides. $\mathrm{E}_{1}$. Bráctea. $\mathrm{E}_{2}$. Flor pistilada (Caruzo 74$)$. $\mathrm{F}_{1}-\mathrm{F}_{3}$. Croton floribundus. $\mathrm{F}_{1}$. Folha. $\mathrm{F}_{2}$. Botão pistilado (Souza 4558). $\mathrm{F}_{3}$. Cálice da flor pistilada com pétalas reduzidas e disco nectarífero (Custodio Filho 391). $\mathrm{G}_{1}-\mathrm{G}_{2}$. Croton glandulosus. $\mathrm{G}_{1}$. Brácteas e profilos. $\mathrm{G}_{2}$. Bráctea (Caruzo 37). $\mathrm{H}_{1}-\mathrm{H}_{2}$. Croton glechomifolius. $\mathrm{H}_{1}$. Folha. $\mathrm{H}_{2}$. Disco nectarífero e pétalas reduzidas da flor pistilada (Mattos 14018-a). $\mathrm{I}_{1}-\mathrm{I}_{4}$. Croton heterodoxus. $\mathrm{I}_{1}$. Folha. $\mathrm{I}_{2}$. Bráctea (Cordeiro 1795). $\mathrm{I}_{3}$. Pétala da flor pistilada. $\mathrm{I}_{4}$. Gineceu (Souza 8879). J. Croton hirtus. Bráctea (Torres 116). $\mathrm{K}_{1}-\mathrm{K}_{3}$. Astraea lobata. $\mathrm{K}_{1}$. Flor pistilada. $\mathrm{K}_{2}$. Lobo do cálice da flor pistilada (Caruzo 55). $\mathrm{K}_{3}$. Semente (Mattos \& Mattos 8512). $\mathrm{L}_{1}-\mathrm{L}_{4}$. Croton lundianus. $\mathrm{L}_{1}$. Glândulas do ápice do pecíolo. $\mathrm{L}_{2}$. Flor estaminada (Caruzo 22). $\mathrm{L}_{3}$. Gineceu. $\mathrm{L}_{4}$. Fruto (Souza 10786). 
Croton organensis Baill., Adansonia 4: 324. 1864. TIPO: BRASIL. Rio DE JANEIRO: "Serra dos Orgãos”, V-1839, Guillemin cat. 938 (holótipo P!).

Material selecionado: BRASIL. São PaUlo: Campos do Jordão, 26-X-2004, M.B.R. Caruzo et al. 72 (SP, SPF, WIS).

Árvore da floresta ombrófila montana do Sudeste do Brasil (MG, RJ, SP).

Croton pedicellatus Kunth, Nov. gen. sp. 2: 75. t. 104. 1817. TIPO: PERU. "Crescit in ripa fluminis Amazonum juxta cataractam Rentemae in Provincia Bracamorensi", alt. 200 hex., Humboldt s.n. (holótipo P!).

Croton corchoropsis Baill., Adansonia 4: 364. 1864. TIPO: BRASIL. MinAs Gerais: Claussen 767 (holótipo P!) syn. nov.

Croton horminum Baill., Adansonia 4: 315. 1864. TIPO: BRASIL. Minas Gerais: Claussen 768 (holótipo M!) syn. nov.

Croton eriocladus Müll. Arg., Fl bras. 11(2): 222. 1873. TIPO: BRASIL. Minas GERAIS: "prope Agoa Suja", Martius s.n. (holótipo M!) syn. nov.

Figuras $2 \mathrm{C}_{1}-\mathrm{C}_{3}$

Material selecionado: BRASIL. SÃo PAUlo: Bauru, 24-II-1998, M.H.O. Pinheiro 727 (HRCB, SP).

Espécie dos cerrados e campos, amplamente distribuída em toda a região neotropical: México, Colômbia, Peru, Bolívia (Govaerts et al. 2000) e Brasil (MA, CE, PI, TO, BA, GO, MT, MS, MG, SP).

Croton piptocalyx Müll Arg., Fl. Bras. 11(2):103. 1873. TIPO: BRASIL. MinAs GERAIS: Lagoa Santa, Warming 1636 (lectótipo C!, aqui designado), Rio DE JANEIRO: "prope Canta Gallo", Peckolt 4 ( síntipo BR n.v.); "in Brasília meridionali prope S. Carlos", Helmreichen 40 (síntipo W!).; "inter Canna Verde et Casa branca", Regnell 1076 (síntipo S n.v.), Pohl (síntipo W!).

Material selecionado: BRASIL. SÃo PAULO: Campinas, 4-XI-2004, M.B.R. Caruzo et al. 79 (SP, WIS).

Árvore das florestas mesófilas do Brasil (BA, MT, MS, MG, RJ, SP). Nomes populares: caixeta, caxeta.

Croton priscus Croizat, Darwiniana 6:454. 1944. TIPO: BRASIL. São Paulo: Santo André, Paranapiacaba, "Alto da Serra", 5-XII-1918, Hoehne s.n. (holótipo SP 2593!, isótipo A!).
Material selecionado: BRASIL. SÃo PaUlo: Santo André, 3-IX-2004, M.B.R. Caruzo et al. 63 (SP).

Arvoreta endêmica do Estado de São Paulo, da floresta ombrófila das encostas da Serra do Mar.

Croton rottlerifolius Baill. Adansonia 4: 327. 1864. TIPO: BRASIL. Minas GeraIs: 1838, Claussen 788 (holótipo P!).

Croton warmingii Müll. Arg., Fl. Bras. 11(2): 105. 1873. TIPO: BRASIL. Minas Gerais: Uberaba, Regnell 1077 (lectótipo UPS!, aqui designado); Lagoa Santa, Warming 1649 (síntipo C!), Riedel 1381, 1382 (síntipo n.v.) syn. nov.

Material selecionado: BRASIL. SÃo PAULO: Campinas, 4-XI-2004, M.B.R. Caruzo et al. 75 (SP, SPF, WIS).

Arbusto a arvoreta da floresta mesófila do Sudeste do Brasil (MG, SP).

Croton salutaris Casar., Nov. stirp. bras. p. 89. 1845. TIPO: BRASIL. Rio DE JANEIRO: "Serra dos Órgãos”, Casaretto 856 (holótipo TO n.v.; isótipo $\mathrm{G} !)$.

Material selecionado: BRASIL. SÃo Paulo: Cunha, 30-XI-2004, M.B.R. Caruzo et al. 81 (SP, SPF, WIS).

Árvore da floresta ombrófila montana e matas ciliares do sudeste (MG, ES, RJ, SP). Nomes populares: cambraia, sangue-de-drago.

Croton sancti-crucis S. Moore, Trans. Linn. Soc. London, Bot. ser. 2, 4: 455. 1895. TIPO: BRASIL. Mato Grosso: "Santa Cruz", Moore 567 (holótipo BM n.v.; isótipo B destruído, foto F!; isótipo WU!). Croton sancti-pauli Croizat, Darwiniana 6: 454. 1944. TIPO: BRASIL. São PaUlo: Barretos, XII-1911, Duarte 8 (holótipo SP!, isótipo A!). syn. nov.

Material selecionado: BRASIL. São PAULO: Cardoso, 1-XIII-1994, L.C. Bernacci et al. 906 (IAC, SP, UEC).

Subarbusto a arbusto dos cerrados do Brasil Central (DF, GO, MS, SP).

Croton sclerocalyx (Didr.) Müll. Arg., Linnaea 34: 134. 1865. Podostachys sclerocalyx Didr., Vidensk. Meddel. Dansk Naturhist. Foren. Kjobenhavn part. 8-10: 134. 1857. TIPO: BRASIL. SÃo PAULO: “campis St. Carlos pr. St. Paulo, I-1834, Lund s.n. (holótipo C!).

Material selecionado: BRASIL. São PAULo: 
Pedregulho, 20¹1'50'S, 47²5'10'W, 16-II-2004, M.B.R. Caruzo et al. 43 (SP).

Subarbusto dos cerrados do Paraguai e Brasil (DF, GO, MT, MG, SP).

Croton serpyllifolius Baill., Adansonia 4: 355. 1864. TIPO: BRASIL. SÃo PAULO: “près d'un ruisseau, dans le voisinage d'Eyneja-Villa", Saint-Hilaire cat. C2 1495 (síntipos P!, A!]; "bords du chemin près de Rincao da Cidade", Saint-Hilaire cat. C2 1580 (síntipos P!, A!).

Material selecionado: BRASIL. São Paulo: Itapeva, 2404'25'S, 4903'09'W, XI-1994, V.C. Souza et al. 7030 (ESA, SP).

Subarbusto dos campos de São Paulo e Paraná.

Croton serratifolius Baill., Adansonia 4: 312. 1864. TIPO: BRASIL. RIo GRANDE do SUL: Saint-Hilaire cat. C2 2704 (holótipo P!, isótipo A!).

Croton garckeanus Baill., Adansonia 4: 308. 1964. TIPO: BRASIL. Rio GRANDE DO SUL: GaudichaudBeaupré 1656 (holótipo P!) syn. nov.

Croton pimeleus Baill., Adansonia 4: 307. 1864. TIPO: BRASIL. Rio GRANDE DO SUl: Saint-Hilaire cat. C2 1391 (holótipo P!) syn. nov.

Figuras $2 \mathrm{~F}_{1}-\mathrm{F}_{5}$

Material selecionado: BRASIL. São PAULO: Itararé, 18-VIII-1995, V.C. Souza et al. 8807 (ESA, SP).

Subarbusto a arbusto dos campos limpos da Argentina, Paraguai e Brasil (MS, SP, PR, SC, RS).

Croton sphaerogynus Baill., Adansonia 4: 326. 1864. TIPO: BRASIL. Rio DE JANEIRo: 1835, Gaudichaud-Beaupré 1139 (lectótipo P!, aqui designado), Minas Gerais: 1842, Claussen 79 (síntipo P!); 1842, Claussen 2004 (síntipo P!).

Figuras $2 \mathrm{G}_{1}-\mathrm{G}_{4}$

Material selecionado: BRASIL. São PAULO: Bertioga, Riviera de São Lourenço, 7-X-2004, M.B.R. Caruzo et al. 67 (SP, WIS).

Arbusto das florestas de restinga e florestas secas do interior do Brasil (BA, MG, ES, RJ, SP).

Croton tricolor Klotzsch ex Baill., Adansonia 4: 291. 1864. TIPO: BRASIL. "In Brasilia meridionali prope Facienda do Funil", Sellow s.n. (lectótipo B destruído, designado por Müller, Linnaea 34: 96. 1865), foto F!, (isolectótipo K!).
Material selecionado: BRASIL. SÃo PAULO: Teodoro Sampaio, 21-II-2005, M.B.R. Caruzo \& L.R. Mendonça-Souza 85 (SP).

Arbusto da floresta mesófila semidecídua da Bolívia e Brasil (SE, PE, BA, MG, SP, PR).

Croton triqueter Lam., Encycl. 2: 214. 1786. TIPO: BRASIL. Rio DE JANeIRo: Commerson s.n. (holótipo P!).

Material selecionado: BRASIL. São PAULO: Itararé, 13-III-2004, M.B.R. Caruzo et al. 27 (SP).

Arbusto da borda de florestas ombrófilas e mesófilas de toda a região neotropical. México, Guatemala, Colômbia, Venezuela, Peru, Bolívia, Paraguai, Argentina e Brasil (RR, MA, CE, PA, PE, SE, BA, ES, MG, GO, MS, RJ, SP, PR, SC, $\mathrm{RS})$.

Croton urucurana Baill., Adansonia 4:335. 1864. TIPO: BRASIL. Saint-Hilaire s.n. [lectótipo P!, designado por Smith et al., Euforbiáceas In Flora Ilustrada Catarinense (R. Reitz ed.) p. 75. 1988], Minas Gerais: Claussen 770 (síntipo P!,), Pissis 9 (síntipo P!).

Croton paulinianus Müll. Arg. Fl. Bras. 11(2): 112. 1873. TIPO: BRASIL. São PAUlo: Burchell 5511 (holótipo K!) syn. nov.

Figuras $2 \mathrm{I}_{1}-\mathrm{I}_{2}$

Material selecionado: BRASIL. São PAULo: Bauru, 24-XII-1996, M.H.O. Pinheiro 236 (HRCB, INPA, SP, UEC, UFMA).

Árvore de pequeno porte, pioneira, amplamente distribuída pelo Paraguai, Argentina, Uruguai e Brasil (BA, GO, DF, MT, MS, MG, ES, RJ, SP, PR, SC, RS) principalmente em matas ciliares, mas também em florestas mesófilas perturbadas e capoeiras. Nome popular: sangra-d'água, sangue-de-drago, pau-desangue e urucurana. Espécie muito utilizada em reflorestamentos.

Croton vulnerarius Baill., Adansonia 4: 328. 1864. TIPO: BRASIL. SÃo PAUlo: Saint-Hilaire cat. C2 1405 (lectótipo P!, aqui designado), Mogi das Cruzes, Saint-Hilaire cat. D 652 (síntipo P n.v.).

Material selecionado: BRASIL. São PAULO: São Paulo, 10-XII-2002, M.B.R. Caruzo et al. 21 (SP).

Arbusto da beira de florestas ombrófilas e mesófilas do Brasil (MG, RJ, SP, PR). 


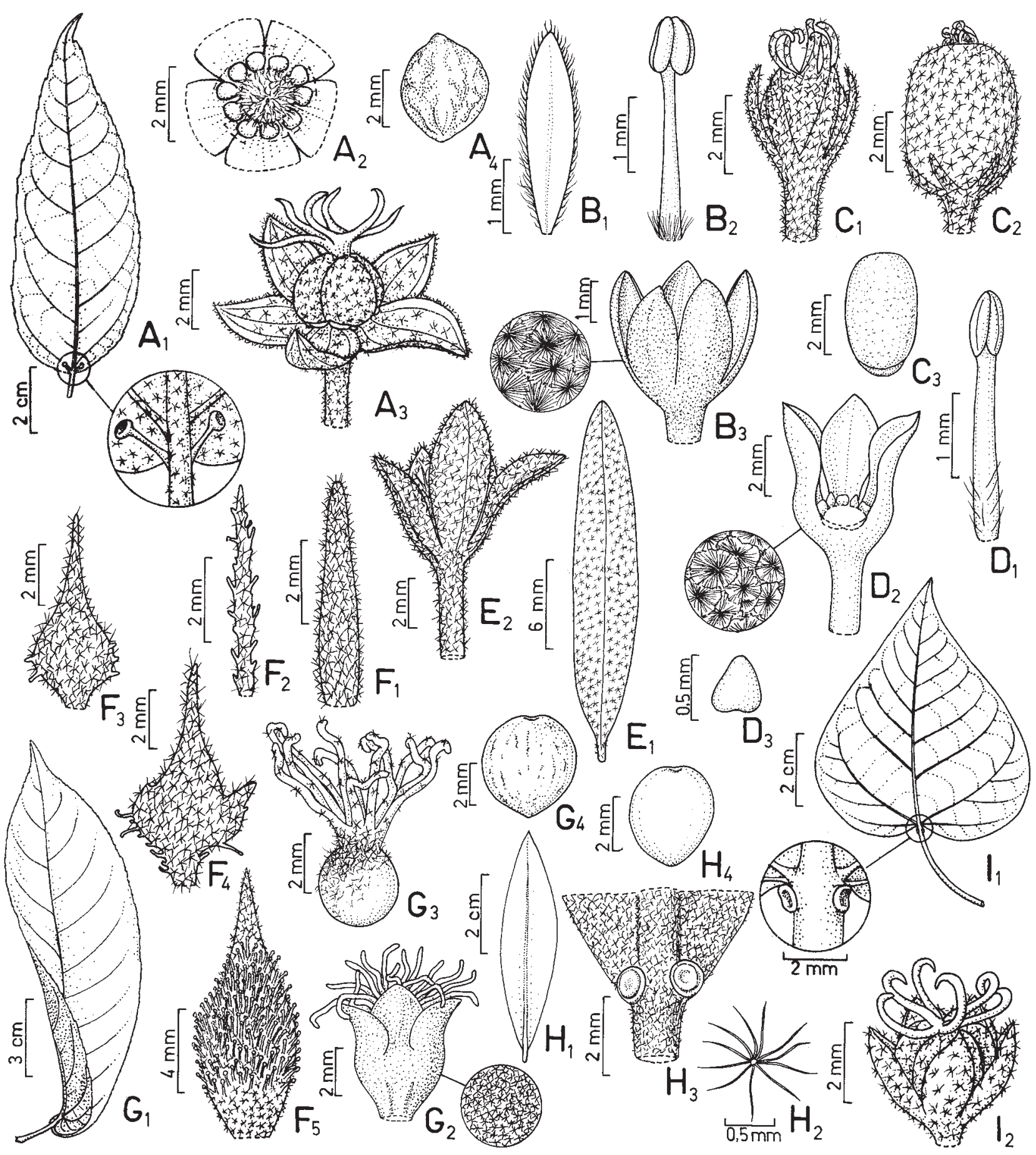

Figura 2. $\mathrm{A}_{1}-\mathrm{A}_{4}$. Croton macrobothrys. $\mathrm{A}_{1}$. Folha (Custodio Filho 31903). $\mathrm{A}_{2}$. Detalhe do disco nectarífero da flor estaminada. $\mathrm{A}_{3}$. Flor pistilada (Lopes 915). $\mathrm{A}_{4}$. Semente (Barros 2014). $\mathrm{B}_{1}-\mathrm{B}_{3}$. Croton ceanothifolius. $\mathrm{B}_{1}$. Pétala da flor estaminada. $\mathrm{B}_{2}$. Estame (Caruzo 68). $\mathrm{B}_{3}$. Flor pistilada (Cordeiro 2772). $\mathrm{C}_{1}-\mathrm{C}_{3}$. Croton pedicellatus. $\mathrm{C}_{1}$. Flor pistilada (Batalha 858). $\mathrm{C}_{2}$. Fruto. $\mathrm{C}_{3}$. Semente (Souza 10955). $\mathrm{D}_{1}-\mathrm{D}_{3}$. Croton salutaris. $\mathrm{D}_{1}$. Estame. $\mathrm{D}_{1}$. Flor pistilada com dois lobos do cálice retirados. $\mathrm{D}_{3}$. Pétala reduzida da flor pistilada (Baitello 638). $\mathrm{E}_{1}-\mathrm{E}_{2}$. Croton. serpyllifolius. $\mathrm{E}_{1}$. Folha. $\mathrm{E}_{2}$. Flor pistilada (Souza 7030). $\mathrm{F}_{1}-\mathrm{F}_{5}$. Croton serratifolius. $\mathrm{F}_{1}$. Estípula inteira. $\mathrm{F}_{2}$. Estípula lacerada. $\mathrm{F}_{3}$. Bráctea inteira. $\mathrm{F}_{4}$. Bráctea partida. $\mathrm{F}_{5}$. Lobo do cálice da flor pistilada (Souza 7146). $\mathrm{G}_{1}-\mathrm{G}_{4}$. Croton sphaerogynus. $\mathrm{G}_{1}$. Folha. $\mathrm{G}_{2}$. Flor pistilada. $\mathrm{G}_{3}$. Gineceu (Kirizawa 3318). $\mathrm{G}_{4}$. Semente (França 2584). $\mathrm{H}_{1}-\mathrm{H}_{4}$. Croton lanatus. $\mathrm{H}_{1}$. Folha. $\mathrm{H}_{2}$. Tricoma estrelado. $\mathrm{H}_{3}$. Glândulas do pecíolo. $\mathrm{H}_{4}$. Semente (Garcia 687). $\mathrm{I}_{1}-\mathrm{I}_{2}$. Croton urucurana. $\mathrm{I}_{1}$. Folha (Bernacci 818). $\mathrm{I}_{2}$. Flor pistilada (Catharino 111). 
Espécies incertas:

Em virtude de não termos localizado os tipos das seguintes espécies descritas para o Estado de São Paulo, as mesmas não foram aqui tratadas: Croton incertus Müll. Arg., Croton josephinus Müll. Arg., Croton occidentalis Müll. Arg., Croton pardinus Müll. Arg. e Croton ypanemensis Müll. Arg.

\section{Agradecimentos}

À Coordenação de Aperfeiçoamento de Pessoal de Nível Superior (CAPES) pela bolsa concedida pelo Departamento de Botânica do Instituto de Biociências da Universidade de São Paulo. Em especial, à desenhista Emiko Naruto in memoriam pela cobertura das ilustrações.

\section{Literatura citada}

APG II. 2003 (Angiosperm Phylogenetic Group). An update of the Angiosperms Phylogenetic Group classification for the orders and families of flowering plants: APG II. Botanical Journal of the Linnean Society 141: 399-436.

Berry, P.E., Cordeiro, I., Wiedenhoeft,A.C., Vitorino-Cruz, M.A. \& Lima, L.R. 2005a. Brasiliocroton, a new crotonoid genus of Euphorbiaceae s.s. from eastern Brazil. Systematic Botany 30: 357-365.

Berry, P.E., Hipp, A.L., Wurdack, K.J., Van Ee, B. \& Riina, R. 2005b. Molecular phylogenetics of the giant genus Croton and tribe Crotoneae (Euphorbiaceae sensu stricto) using ITS and trnL-trnF DNA sequence data. American Journal of Botany 92: 1520-1534.

Burger, W. \& Huft, M. 1995. Flora costaricensis: Euphorbiaceae. Fieldiana, Bot, n.s. 36: 1-169.

Chase, M.W., Zmarzty, S., Lledó, M.D., Wurdack, K.J., Swensen, S.M. \& Fay, M.F. 2002. When in doubt, put in Flacourtiaceae: a molecular phylogenetic analysis based on plastid $r b c L$ DNA sequences. Kew Bulletin 57: 141-181.

Cordeiro, I. 1993. Revisão taxonômica de Julocroton Mart. (Euphorbiaceae). Tese de Doutorado, Universidade de São Paulo, São Paulo.
Govaerts, R., Frodin, D.G. \& Radcliffe-Smith, A. 2000. World Checklist and Bibliography of Euphorbiaceae (and Pandaceae), v. 2. Kew, Royal Botanical Gardens.

Hoehne, F.C., Kuhlmann, M. \& Handro, O. 1841. O Jardim Botânico de São Paulo. Secretaria de Agricultura, Indústria e Comércio de São Paulo, São Paulo.

Mcneill, J., Barrie, F.R., Burdet, H.M., Demoulin, V., Hawksworth, D.L., Marlhold, K., Nicolson, D.H., Prado, J., Silva, P.C., Skog, J.E., Wiersema, J.H. \& Turland, N.J. (eds.). 2006. International Code of Botanical Nomenclature (Vienna Code), adopted by the Seventeenth International Botanical Congress Vienna, Austria, July 2005. A.R.G. Gantner Verlag, Ruggell. [Regnum Veg. 146]

Müller, J. 1865. Euphorbiaceae. Linnaea 34: 1-224.

Müller, J. 1866. Euphorbiaceae exceto subordo Euphorbieae. In Prodromus Systematics Universalis Regni Vegetabilis (A.P. De Candolle, ed.) 15: 189-1286.

Müller, J. 1873/1874. Euphorbiaceae. In: C.F.P. Martius \& A.G. Eichler (eds.). Flora Brasiliensis 11: 1-750, pl. 1-104.

Riina, R. 2006. Molecular systematics of the neotropical dragon's blood trees Croton sec. Cyclostigma (Euphorbiaceae). Phd thesis. University of WisconsinMadison.

Smith, L.B., Downs, R.J. \& Klein, R.M. 1988. Euforbiáceas. In: R. Reitz (ed.). Flora Ilustrada Catarinense. pp. 1-137.

Urban, I. 1906. Vitae itineraque collectorum botanicorum, notae collaboratum biographicae, Florae brasiliensis ratio edendi chronologica, systema, index familiarum. In: C.F.P. Martius \& A.G. Eichler (eds.). Flora Brasiliensis 1: $1-268$.

Webster, G.L. 1992. Realignments in American Croton (Euphorbiaceae). Novon 2: 269-273.

Webster, G.L. 1994. Systematics of the Euphorbiaceae. Annals of the Missouri Botanical Garden 81:1-144.

Webster, G.L. 2001. Synopsis of Croton and Phyllanthus (Euphorbiaceae) in Western Tropical Mexico. Contributions from the University of Michigan Herbarium 23: 353-388.

Wurdack, K.J., Hoffmann, P. \& Chase, M.W. 2005. Molecular phylogenetics analysis of uniovulate Euphorbiaceae (Euphorbiaceae sensu stricto) using plastid rbcL and trnL-F DNA sequences. American Journal of Botany 92 : 1397-1420. 